\title{
GCU
}

Glasgow Caledonian

University

University for the Common Good

\section{Racking performance of platform timber framed walls assessed by rigid body relaxation technique}

D'Amico, B.; Kermani, A.; Porteous, J.; Dhonju, R.; Zhang, B.

Published in:

Construction and Building Materials

DOI:

10.1016/j.conbuildmat.2016.10.106

Publication date:

2016

Document Version

Author accepted manuscript

Link to publication in ResearchOnline

Citation for published version (Harvard):

D'Amico, B, Kermani, A, Porteous, J, Dhonju, R \& Zhang, B 2016, 'Racking performance of platform timber framed walls assessed by rigid body relaxation technique', Construction and Building Materials, vol. 129, pp. 148-158. https://doi.org/10.1016/j.conbuildmat.2016.10.106

\section{General rights}

Copyright and moral rights for the publications made accessible in the public portal are retained by the authors and/or other copyright owners and it is a condition of accessing publications that users recognise and abide by the legal requirements associated with these rights.

Take down policy

If you believe that this document breaches copyright please view our takedown policy at https://edshare.gcu.ac.uk/id/eprint/5179 for details of how to contact us. 


\title{
Racking performance of Platform timber framed walls assessed by rigid body relaxation technique
}

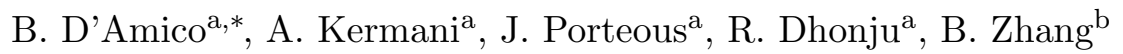 \\ ${ }^{a}$ Centre for Timber Engineering (CTE), School of Engineering and the Built Environment, Edinburgh \\ Napier University, Edinburgh, UK \\ ${ }^{b}$ School of Engineering and Built Environment, Glasgow Caledonian University, Glasgow, UK
}

\begin{abstract}
A new method to assess the raking performance of Platform timber framed walls, is provided in this study: each component of the unit wall assembly is assumed as rigid, hence allowing to drastically reduce the overall number of DoFs involved within the model. The timber frame in particular, is modelled as a mechanism, having only two DoFs (regardless of the number of studs) corresponding to the horizontal and rotational displacements of the header beam. For a given imposed horizontal displacement $\Delta_{h}$, the corresponding racking load $P\left(\Delta_{h}\right)$ is computed by numerical relaxation, allowing to consider a continuous function to represent the load-slip curves of the connections. A comparison of the numerical analysis against laboratory test results is provided, showing the method's capability in predicting the raking strength of the wall, despite the assumed reduced number of DoFs.
\end{abstract}

Keywords: Platform framing, Timber framed walls, Raking performance, Dynamic relaxation, Non-linear analysis

\section{Introduction}

First introduced in North America, the Platform timber frame is a widespread construction method for both single and low to mid-rise multi-storey buildings [1]. The method lends itself to the use of prefabricated elements manufactured off-site under quality controlled conditions and benefits from improved quality, reduced construction time and costs $[2,3]$. In the Platform construction method, walls are formed on site

\footnotetext{
* Corresponding author, telephone: +44 (0) 1314552540

Email addresses: b.d'amico@napier.ac.uk (B. D'Amico), a.kermani@napier.ac.uk (A. Kermani), j.porteous@napier.ac.uk (J. Porteous), r.dhonju@napier.ac.uk (R. Dhonju), Ben.Zhang@gcu.ac.uk (B. Zhang) 


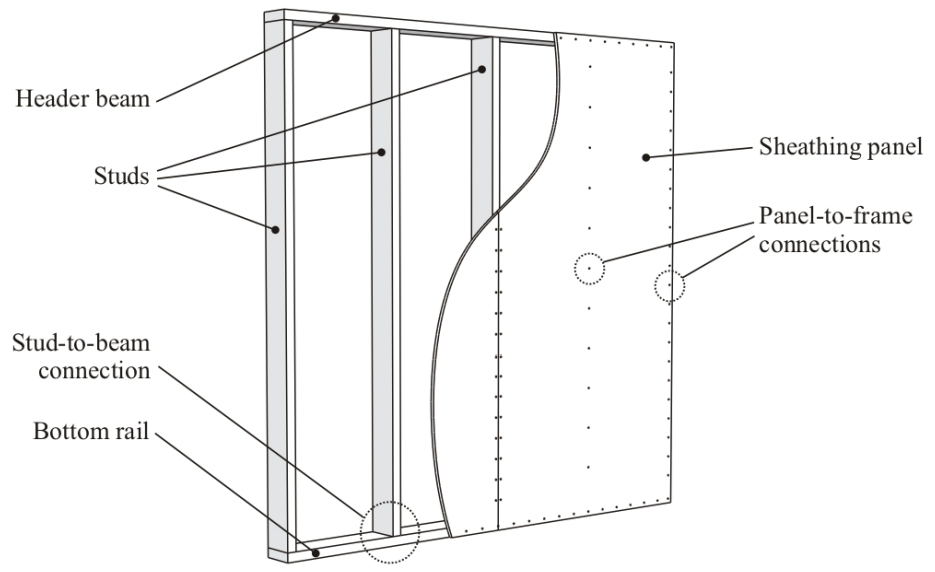

Figure 1: Schematic representation of a unit timber framed wall and its components.

by side-joining single story unit wall panels that have been prefabricated off-site in a factory environment. The floor structure is then fixed to the top of the walls and that forms a Platform from which the prefabricated walls for the next storey can be erected. The prefabricated wall panels are formed by assembling a timber frame composed of vertical and horizontal members (commonly referred to as studs and beams respectively) with a sheathing material, such as Oriented Strand Board (OSB), Particleboard or Plywood. The sheathing is fixed to one or both faces of the frame by mechanical fastening, e.g. nails, staples or screws. A schematic representation of the unit wall and its components is shown in Figure 1. From a structural point of view, the function of the studs is to provide vertical support for loading coming from the above floor/walls, as well as provide means of connecting adjacent wall panels in each storey to form wall diaphragms. The beam elements provide a solid base onto which the wall diaphragms (and floor structures) can be secured to provide vertical and horizontal anchorage. The structural function of the sheathing panels is essentially to work as a system with the timber frame, in order to provide in-plane racking stiffness and strength to the wall diaphragms against horizontal loading arising from lateral actions such as wind and/or earthquake. The aim of this paper is to present a numerical method for assessing the racking stiffness and strength of such walls through the application of a rigid body relaxation technique.

\subsection{Reasons for the use of a rigid body approach}

Limiting the content of the paper to the case of timber framed walls subjected to a monotonic, static loading regime; two main subsets of analysis methods can be found 
within literature:

- Analytical models

- Iterative (numerical) methods

Analytical models enable to predict the raking behaviour of the wall by simple hand calculations, which are suitable for design purposes and usually only provide strength results. Indeed, modelling the complex mechanics of the behaviour of a wall with a closed-form equation is only possible if simplifications of the behaviour of the wall are made. Such simplifications may relate to the stud-to-frame connections which, for example, can be modelled as perfect hinges $[4,5]$ or assumed to have a linear elastic stiffness behaviour against uplift reaction forces $[6,7]$. Design solutions to nearly match such theoretical models can be achieved by anchoring the studs to the wall's substructure e.g. by means of holding-down brackets. However, where such a measure is not to be used in the construction process, the uplifting forces arising in the non-anchored, or partially anchored frame, will trigger a mechanism of separation at the bottom stud-tobeam connections (most pronounced on the windward side of the wall) which must be taken into account to be able to predict the wall's racking strength with an acceptable degree of accuracy. In regard to this, Källsner and Girhammar [8, 9] developed closed form solutions suitable for hand calculations that are loosely based on the theory of plasticity [10] to provide a conservative result (i.e. lower bond values). For instance, the current design method in UK for timber raking walls, as given in the PD 6693-1 document [11, 12], is partially based on their plastic model [13].

Unlike analytical models, iterative methods are able to achieve a great level of accuracy in reproducing the mechanical behaviour of the wall since material and geometric non-linearities can be fully accounted for, especially with regard to the non-linear behaviour of the connections. Mainly compiled using Finite Element (FE) methods, the primary use of such models falls within the context of research and product development, e.g. to carry out simulation testing and parametric analyses. Recent developments on the modelling of racking timber framed walls using the FE method can be found in $[14,15]$.

Although such FE methods are readily available for commercial use, the benefit of proposing an alternative rigid body relaxation technique relies on the assumption of rigid behaviour for the timber frame wall components, which underpins most of the analytical design models. Such a widely accepted assumption is based on the understanding 
that because of the stiffness/strength properties of the wall panel connections, the deformations of the various members making up the unit wall assembly (i.e. studs, beams and sheathing panels) only plays a marginal role in determining the overall horizontal displacement of the wall, which is in fact greatly influenced by the stiffness/strength properties of its connections. On this basis, it is reasonable to model the wall assembly as a set of rigid bodies connected to each other by means of springs reproducing the system of fasteners holding the assembly together. Furthermore, whilst it is understood that nothing prevents the use of rigid body simulation within a FE framework, the underlying functioning of the FE analysis is often not transparent and readily understood by the analyst (the so called 'black-box syndrome' [16]). The benefit of the rigid body relaxation method which is addressed in this paper, is that it uses simple vector algebra operations, e.g. to describe the torque/lever-arm relationship, and by doing so, it provides a direct and more intuitive link between concepts a Platform design engineer is more familiar with, (e.g. stabilising/overturning moments) and the underlying functioning of the method itself.

The theoretical basis of the rigid body relaxation method is described in detail within the following section, whilst in section 3 there is a comparison between the strength and stiffness behaviour of racking walls based on the application of this method and the results of three walls subjected to racking test.

\section{Theory}

The rigid body relaxation method described is this section is an extension to rigid bodies of the Dynamic Relaxation technique, which is a numerical method introduced by Day [17]. The method is particularly suitable for solving structural engineering problems involving a high degree of non-linearity, such as the form-finding/analysis of tension structures [18] and grid-shells $[19,20]$, and it is particularly suited for parallel computing schemes [21].

\subsection{Fully hinged timber frame}

As already pointed out in the Introduction, for a fully anchored ${ }^{1}$ timber framed wall the stud-to-beam connections can be assumed to behave as hinged joints. Where

\footnotetext{
${ }^{1}$ The term 'fully anchored' is referred in this paper to the timber frame only. There can be situations in which the timber frame, as well as the sheathing panels, will be anchored to the underlying floor/foundation but the behaviour of such walls will not comply with the modelling assumptions presented in this paper.
} 


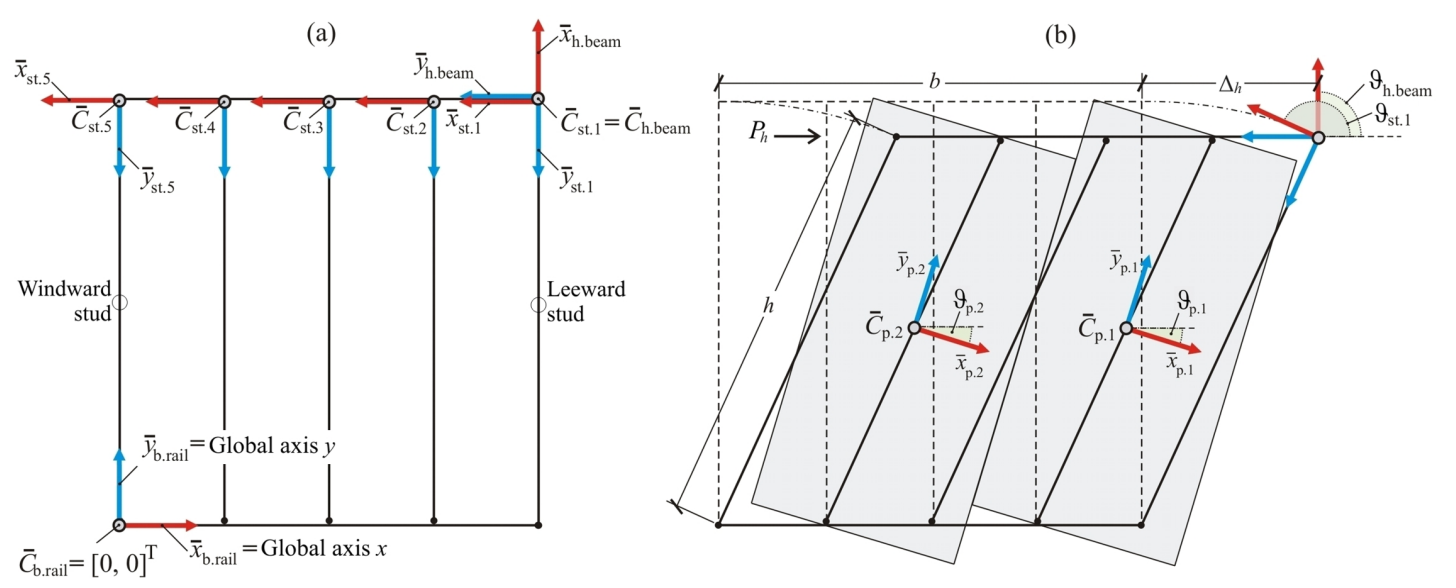

Figure 2: Rigid body modelling of the unit wall's components: each component (stud, beam or panel) is uniquely defined by a centre of rotation, $\bar{C}$, and a local coordinate system, $\{\bar{x} ; \bar{y}\}$ which is a function of the orientation angle $\vartheta$ with respect to the global coordinate system $\left([1,0]^{\top} ;[0,1]^{\top}\right)$.

that is the case - and using the assumption of rigid behaviour - the resulting timber frame assembly will resemble a mechanism having only one degree of freedom, e.g. there will be a horizontal displacement $\Delta_{h}$ (see Figure 2-b) arising from the application of a horizontal load $P_{h}$ applied to the header beam.

For a given value of $\Delta_{h}$ the sheathing panels will assume a configuration of static equilibrium at which the total strain energy of the panel-to-frame connections is at its minimum. Assuming for instance a linear-elastic behaviour up to failure for the panelto-frame connections, position and orientation of static equilibrium for the panels (as well as the corresponding wall racking strength) can be derived by application of the principle of virtual work, as shown by Källsner and Girhammar [4]. However, fastener behaviour is not linear and for the more realistic case of non-linear behaviour of the panel-to-frame connections, the configuration of equilibrium for the sheathing panels and corresponding racking load $P_{h}$ of the wall, can be obtained by using an iterative procedure as discussed in this paper.

\subsubsection{Parametrisation of the timber frame geometry}

Before describing the iterative procedure, the hinged frame geometry must be defined as a function of the parameter $\Delta_{h}$. A convenient method is to express the position and orientation of the various rigid bodies making up the timber frame (as well as the panels) using a centre of rotation $\bar{C}_{j}$ and a local orthonormal basis $\left\{\bar{x}_{j} ; \bar{y}_{j}\right\}$ for the $j$ th rigid body element. It is worth noting that such centres of rotation do not have to 
coincide with the gravity centre of the element, rather, they can be arbitrarily chosen and the convention adopted in here is shown in Figure 2-a, for the timber members. The rotation centres of the studs are positioned at their top end; the rotation centre of the header beam coincides with that of the leeward (right) stud and the centre of rotation of the bottom rail coincides with the origin of the global (Cartesian) reference axes. The global axes are defined on Figure 2-a.

The centres of rotation for the panels are set to coincide with their centroid position (see Figure 2-b). All the rotation centres may be grouped into vector lists according to the type of member they belong to, i.e. $\mathbf{C}_{\text {beams }}$ for beams, $\mathbf{C}_{\text {studs }}$ for studs and $\mathbf{C}_{\text {panels }}$ for the panels:

$$
\begin{gathered}
\mathbf{C}_{\text {beams }}=\left\{\bar{C}_{\text {b.rail }} ; \bar{C}_{\text {h.beam }}\right\} \\
\mathbf{C}_{\text {studs }}=\left\{\bar{C}_{s t .1} \ldots \bar{C}_{\text {st. } j} \ldots \bar{C}_{\text {st. } n_{s t .}}\right\} \\
\mathbf{C}_{\text {panels }}=\left\{\bar{C}_{p .1} \ldots \bar{C}_{p . j} \ldots \bar{C}_{p . n_{p}}\right\}
\end{gathered}
$$

with the subscripts $n_{s t}$. and $n_{p}$ indicating the total number of studs and panels, respectively, in the unit wall. From the chosen convention, the vector components in the bi-dimensional Cartesian space for each centre of rotation of the timber frame members, will be:

$$
\begin{gathered}
\bar{C}_{\text {b.rail }}=\left[\begin{array}{l}
0 \\
0
\end{array}\right] ; \quad \bar{C}_{h . \text { beam }}=\left[\begin{array}{c}
b+\Delta_{h} \\
\sqrt{h^{2}-\Delta_{h}^{2}}
\end{array}\right] \\
\bar{C}_{\text {st.j }}=\bar{C}_{\text {h.beam }}+\left(\frac{j-1}{n_{\text {st. }}-1} b\right) \bar{y}_{h . b e a m} \quad \text { with } j=1 \ldots n_{\text {st. }}
\end{gathered}
$$

where $b$ and $h$ are the wall's width and height respectively, whilst $\bar{y}_{h . b e a m}$ is the header beam's unit local axis along its longitudinal direction, as shown in Figure 2. Such a unit vector, together with its normal $\bar{x}_{h . b e a m}$, describes the orientation of the header beam in the bi-dimensional plane, as for all of the remaining studs, plate and panels. For the $j$ th member, the corresponding local coordinate systems $\left\{\bar{x}_{j} ; \bar{y}_{j}\right\}$ can be extracted from the scalar $\vartheta_{j}$ representing the angle between the global (Cartesian) and local axes directions, as also shown in Figure 2-b. In practice, each unit vector $\bar{x}, \bar{y}$ is obtained by pre-multiplying the global axes $\left([1,0]^{\top} ;[0,1]^{\top}\right)$ with a rotation matrix whose terms 
are functions of $\vartheta$ :

$$
\bar{x}=\left[\begin{array}{cc}
\cos \vartheta & -\sin \vartheta \\
\sin \vartheta & \cos \vartheta
\end{array}\right] \cdot\left[\begin{array}{l}
1 \\
0
\end{array}\right] \quad ; \quad \bar{y}=\left[\begin{array}{cc}
\cos \vartheta & -\sin \vartheta \\
\sin \vartheta & \cos \vartheta
\end{array}\right] \cdot\left[\begin{array}{l}
0 \\
1
\end{array}\right]
$$

and, according to the chosen convention (see Figure 2-b), the orientation angles for each member of the timber frame will be:

$$
\begin{gathered}
\vartheta_{\text {b.rail }}=0 ; \vartheta_{\text {h.beam }}=\frac{\pi}{2} \\
\vartheta_{\text {st. } j}=\pi-\arcsin \left(\frac{C_{\text {st. } j, x}-b \frac{n_{\text {st. }}-j}{n_{\text {st. }}-1}}{\left\|\bar{C}_{s t . j}-b\left[\frac{n_{s t .}-j}{n_{s t .}-1}, 0\right]^{\top}\right\|}\right) \quad \text { with } j=1 \ldots n_{\text {st. }}
\end{gathered}
$$

where $C_{s t . j, x}$ is the horizontal component of $\bar{C}_{s t . j}$. As can be observed from Eq. (8), the orientation angle of the studs is a function of their centre of rotation, which, from Eq. (5), is a function of the header beam's rotation centre and orientation. Further, from the second of Eqs. (4), these are only functions of the wall geometry and imposed displacement $\Delta_{h}$. In other words: the whole geometry of the timber frame is uniquely defined by the single parameter $\Delta_{h}$ corresponding to the degree of freedom of the frame mechanism. It is worth pointing out that a simpler expression for $\vartheta_{s t . j}$ in terms of $\Delta_{h}$ is given in $\mathrm{Eq}(9)$ :

$$
\vartheta_{s t . j}=\pi-\arcsin \left(\frac{\Delta_{h}}{h}\right)
$$

however, Eq.(9) is only valid if there is no rotation of the header beam. Since rotation of the header beam must be taken into account when addressing partially anchored walls (section 2.2), the chosen parametrisation (Eq. (8)) will hold for both cases. Furthermore, it is to be noted that for Eqs. (5) and (8) to work, each $\bar{C}_{s t . j}$ item in the $\mathbf{C}_{\text {studs }}$ list must be sorted in ascending order, starting from the centre of rotation of the leeward stud $\left(=\bar{C}_{s t .1}\right)$ and moving toward the left, up to the centre of rotation of the windward stud $=\bar{C}_{\text {st. }}$ st. as shown in Figure 2-a.

The parametrisation used in this paper to describe the timber frame deformation, is based on the assumption that the bottom rail does not experience any upward movement under the effect of a racking force.

\subsubsection{Iterative procedure}

With the timber frame geometry defined, the remaining unknowns, required to completely define the deformed geometry of the wall, are the centres of rotation and orienta- 
tion angles of the sheathing panels: $\bar{C}_{p . j}$ and $\vartheta_{p . j}$ respectively. These quantities depend on the resultant of forces and moment applied to the panels, due to the reaction forces from the panel-to-frame connections. For instance, in the trivial case for which no horizontal displacement is imposed on the timber frame (i.e. $\Delta_{h}=0$ ), the force/moment resultants will be zero, which means centres of rotation and orientation angles will only depend on the convention chosen to describe the panels' initial position in the Cartesian space. For instance, $\bar{C}_{p . j}$ has been positioned in this paper to coincide with the centroid of the $j$ th panel, and for $\Delta_{h}=0$, its local coordinate system $\left\{\bar{x}_{1 . j} ; \bar{y}_{2 . j}\right\}$ will be aligned with the global coordinate system, i.e. for $\Delta_{h}=0$, then $\vartheta_{p . j}=0$.

As soon as a displacement $\Delta_{h}>0$ is imposed to the timber frame, out-of-balance forces $\bar{R}_{j}$ and moments $M_{j}$ (acting on the $j$ th panel) will arise and the requirement is to find the updated values of $\bar{C}_{p . j}$ and $\vartheta_{p . j}$ for which $\bar{R}_{j}$ and $M_{j}$ will be zero again. This can be achieved by expressing the translational acceleration of the $j$ th panel as vector $\bar{a}_{j}$ which, according to Newton's second law of motion, will be a function of the body's mass $(m)$ and the resultant of the out-of-balance force $\bar{R}_{j}$ :

$$
\bar{a}_{j}=\frac{\bar{R}_{j}}{m}
$$

hence, by performing a double numerical integration over the time domain, the velocity term, and eventually the increment of displacement, can be obtained. Adopting for instance the 4th order Runge-Kutta integration method [22], the velocity $\bar{v}_{j}$ for the $j$ th rigid body (panel) at time ' $t+\Delta t$ ' will be computed from the acceleration and velocity terms at time ' $t$ ' as follows:

$$
\bar{v}_{j}^{t+\Delta t}=\xi \bar{v}_{j}^{t}+\frac{\Delta t}{6}\left(\bar{k}_{1}+2 \bar{k}_{2}+2 \bar{k}_{3}+\bar{k}_{4}\right)
$$

with the terms $\bar{k}_{1}$ to $\bar{k}_{4}$ derived as given in Eq. (9) of [23], where $\xi$ is a viscous damping term (having a value between 0 and 1 , usually $0.9 \leq \xi \leq 0.999$ ) that is required for the rigid body to eventually attain a position of rest equilibrium. With the velocity vector $\bar{v}_{j}^{t+\Delta t}$ so obtained, the position of the rigid body (i.e. the position of its centre of rotation $\bar{C}_{j}$ ) updated at time ' $t+\Delta t$ ' will be computed as follows:

$$
\bar{C}_{j}^{t+\Delta t}=\bar{C}_{j}^{t}+\frac{\Delta t}{6}\left(\bar{k}_{1}+2 \bar{k}_{2}+2 \bar{k}_{3}+\bar{k}_{4}\right)
$$

where the terms $\bar{k}_{1}$ to $\bar{k}_{4}$ are those given in Eq. (10) of [23].

The same iterative procedure described in Eqs. (11) and (12) is then applied to find the orientation angle $\vartheta_{j}$ of rest equilibrium. For this condition, setting $a_{j}$ as the scalar 
value of the rigid body's angular acceleration; replacing the residual vector force $\bar{R}_{j}$ in Eq. (10) with the residual moment $M_{j}$ and setting $m$ to be the moment of inertia of the panel (i.e. $a_{j}=M_{j} / m$ ), the orientation angles $\vartheta_{j}$, updated from time ' $t$ ' to time ' $t+\Delta t$ ' will eventually found to be:

$$
\vartheta_{j}^{t+\Delta t}=\vartheta_{j}^{t}+\frac{\Delta t}{6}\left(\bar{k}_{1}+2 \bar{k}_{2}+2 \bar{k}_{3}+\bar{k}_{4}\right)
$$

The procedure described above is applied iteratively by keeping a fixed geometry for the timber frame, i.e. keeping a fixed imposed displacement $\Delta_{h}$. So, by updating the out-of-balance forces $\bar{R}$ and moments $M$ in Eqs. (11) for each time increment, until they become small enough to be able to be neglected, it can then be assumed the system will have achieved static equilibrium. At this stage, the racking load $P\left(\Delta_{h}\right)$ acting on the unit wall can be derived as described in section 2.1.4. A further increment of horizontal displacement is then imposed, and the updated value of $P$ and associated displacement will be derived as described above, and by continuing with this procedure, the entire load-displacement curve of the wall will be obtained. The analysis can be started by setting the acceleration and velocity terms $\left(\bar{a}_{j}^{t=0} ; \bar{v}_{j}^{t=0}\right)$ as being equal to zero.

An important fact to note is that when implementing the described procedure, since we are not interested in tracing the real dynamic behaviour of the wall, the analysis process can be speeded up by using fictitious values for the masses $(m)$, inertia moments and viscous damping factor $(\xi)$. These can be set to reduce the total number of required iterations but still ensure numerical convergence will be achieved at the same time. This approach is greatly dependent on the ratio between mass value and time increment $\Delta t$. Numerically stable $m / \Delta t$ ratios will be proportional to the frequency vibration of the system. The values of $m, \xi$ and $\Delta t$, set for the analyses covered in section 3 , were calibrated by trial-end-error. As opposed to Stiffness Matrix methods which achieve convergence by using a Newton-Raphson solver, providing a stable mass/time-step ratio is used, the explicit method described in this paper is insensitive to discontinuities of the load-displacement relationship in converging to the solution.

\subsubsection{Computing residual forces and moments}

In order for the method to be implemented, it is evident from Eqs. (11) that, for each sheathing panel, residual reaction forces $\bar{R}$ and moments $M$ need to be computed at each time increment. These reactions come from the combined action of the panelto-frame connections surrounding each panel and holding the wall assembly together. 


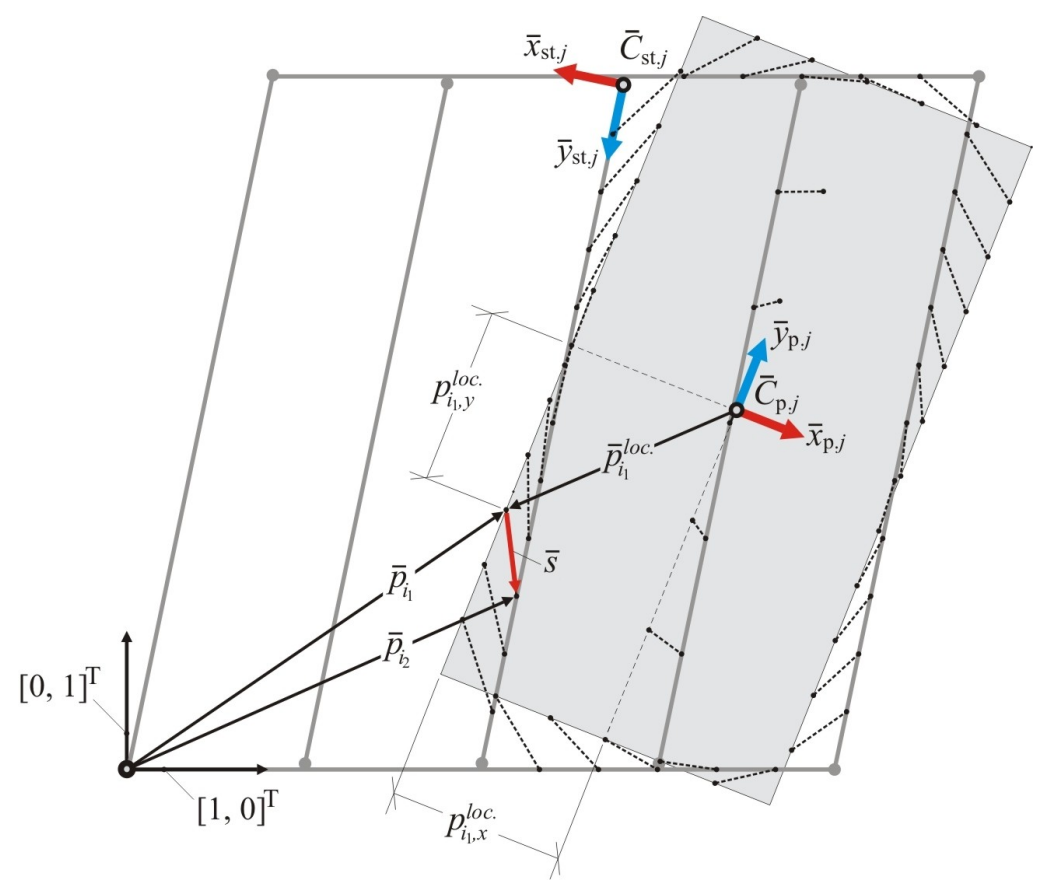

Figure 3: Vector slip $\bar{s}$ of the generic panel-to-frame connection expressed in terms of global $\left(\bar{p}_{i_{1}} ; \bar{p}_{i_{2}}\right)$ coordinates and local $\left(\bar{p}_{i_{1}}^{\text {loc. }} ; \bar{p}_{i_{2}}^{l o c .}\right)$ coordinates.

This can be expressed as:

$$
\bar{R}_{j}^{t}=\sum_{i=1}^{n_{c}} \bar{F}_{j, i}^{t}
$$

in which: $\bar{F}_{j, i}^{t}$ is the in-plane reaction (at time ' $t$ ') of the $i$ th panel-to-frame connection acting on the $j$ th panel, and $n_{c}$ is the total number of connections fixing the panel to the timber frame. The panel-to-frame load-slip behaviour is a function of the direction of the fastener load relative to the timber grain, with loading perpendicular to the grain giving a lower strength value. To simplify the process, the connection has been modelled as a simple axial spring, allowing the force $F$ in Eq. (14) to be derived from the characteristic load-slip curve of the connection and to ensure a conservative value is used, results were derived from tests in which the fastener load is applied at right angles to the grain. The test results are referred to in section 3.2.

From the test data, the load-slip curve can be modelled as a continuous function, $f(s)$, and using the approach defined in [24], in which five parameters associated with the behaviour of the connection are used to derive the curve, the vector $\bar{F}$ to insert in 
Eq. (14) can be derived as follows:

$$
\bar{F}^{t}=\frac{\bar{s}^{t}}{s^{t}} f\left(s^{t}\right) \quad \text { with } s=\|\bar{s}\|
$$

where $\bar{s}^{t}$ indicates the vector connecting the two ends of the axial spring at time ' $t$ '. Clearly, the slip vector $\bar{s}$ of each spring, is constantly changing during the analysis. With reference to Figure 3, the slip vector for the $i$ th spring, connecting the $j$ th panel to the timber frame at time ' $t$ ', is given by:

$$
\bar{s}^{t}=\bar{p}_{i_{2}}^{t}-\bar{p}_{i_{1}}^{t}
$$

where $\bar{p}_{i_{1}}$ and $\bar{p}_{i_{2}}$ are, respectively, the position vectors of the spring's end-node 1 and end-node 2. Because of the rigid body assumption, the position of the spring's end nodes $(1,2)$ does not change over time with respect to the local coordinate system of the rigid bodies they belong to. Therefore, Eq. (16) can be rearranged in terms of local coordinates as follows (see Figure 3):

$$
\bar{s}^{t}=\left(\bar{C}_{s t . j}^{t}+p_{i_{2}, x}^{l o c} \bar{x}_{s t . j}^{t}+p_{i_{2}, y}^{l o c .} \bar{y}_{s t . j}^{t}\right)-\left(\bar{C}_{p . j}^{t}+p_{i_{1}, x}^{l o c .} \bar{x}_{p . j}^{t}+p_{i_{1}, y}^{l o c .} \bar{y}_{p . j}^{t}\right)
$$

in which:

$$
\bar{p}_{i_{1}}^{\text {loc. }}=\left[\begin{array}{c}
p_{i_{1}, x}^{\text {loc. }} \\
p_{i_{1}, y}^{\text {loc. }}
\end{array}\right] \quad ; \quad \bar{p}_{i_{2}}^{\text {loc. }}=\left[\begin{array}{c}
p_{i_{2}, x}^{\text {loc. }} \\
p_{i_{2}, y}^{\text {loc. }}
\end{array}\right]
$$

are respectively: the position vector of the spring's end-node 1 measured with respect to $\left\{\bar{x}_{p . j} ; \bar{y}_{p . j}\right\}$ and the position vector of the spring's end-node 2 measured with respect to $\left\{\bar{x}_{s t . j} ; \bar{y}_{s t . j}\right\}$. From Eq. (17) the slip vector $\bar{s}$ of each panel-to-frame connection can be calculated by only knowing the position and orientation angle of the corresponding rigid bodies. The equation will equally apply to the derivation of the position vector for the connections between panels and beams.

As for the reaction force $\bar{R}$, a residual (out-of-balance) moment $M$ for each sheathing panel, needs to be computed at each time increment. This task is carried out for the $j$ th panel by summing up the various moments generated by the $i$ th connection, that is to say: by summing up the components of $\bar{F}_{j, i}$ multiplied by the corresponding (vertical, horizontal) lever-arm around the centre of rotation $\bar{C}_{p . j}$ :

$$
M_{j}^{t}=\sum_{i=1}^{n_{c}} F_{j, i, y}^{t}\left(p_{i_{1}, x}^{t}-C_{p . j, x}^{t}\right)-F_{j, i, x}^{t}\left(p_{i_{1}, y}^{t}-C_{p . j, y}^{t}\right)
$$

255 in which:

$$
\bar{p}_{i_{1}}=\left[\begin{array}{c}
p_{i_{1}, x} \\
p_{i_{1}, y}
\end{array}\right] \quad ; \quad \bar{F}_{j, i}=\left[\begin{array}{c}
F_{j, i, x} \\
F_{j, i, y}
\end{array}\right] \quad ; \quad \bar{C}_{p . j}=\left[\begin{array}{l}
C_{p . j, x} \\
C_{p . j, y}
\end{array}\right]
$$




\subsubsection{Computing the racking load}

By following the described procedure, for a given horizontal displacement $\Delta_{h}$ imposed on the unit wall, it is possible to find the corresponding deformed geometry. However, the primary requirement is the derivation of the associated horizontal (racking) load $P_{h}$ at $\Delta_{h}$ and this is achieved by summing the horizontal ( $x$ direction) forces in the header beam, i.e:

$$
\text { Action }=-\sum \text { Reactions }
$$

more precisely:

$$
P_{h}=-\left[R_{h . b e a m, x}+\left(\sum_{j=1}^{n_{s t .}} R_{s t . j, x}+T_{s t . j, x}\right)\right]
$$

in which, the vector reaction force of the header beam (i.e. $\bar{R}_{h \text {.beam }}$ ) and reaction vectors of the studs (i.e. $\bar{R}_{s t . j}$ ) are derived following the same procedure as described for the panels in Eq. (14) to (17). However, the slip vector $\bar{s}$ to use in Eq. (15) will be opposite in direction compared to that computed with Eq. (16), i.e:

$$
\bar{s}=\bar{p}_{i_{1}}-\bar{p}_{i_{2}}
$$

this is because the force $\bar{F}$ of the panel-to-frame connections is acting on the timber frame, not on the panels. Further, as the centre of rotation of each stud $\left(\bar{C}_{s t . j}\right)$ is positioned at the header beam, as shown in Figure 2-a, there will be a reaction force $\left(R_{s t . j, x}\right)$ from each stud. Also, the reaction moment $\left(M_{s t . j}\right)$ of the $j$ th pinned stud, will generate free body shear forces at the end nodes of the studs, defined as $\bar{T}_{s t . j}$.

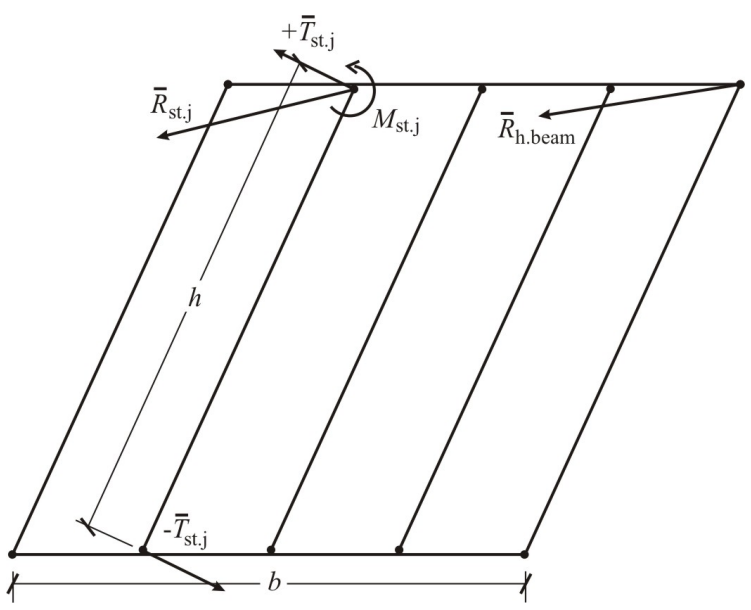

Figure 4: Computing of the wall raking load by imposing the equilibrium to translation between external actions and internal reaction forces $\bar{R}_{h . b e a m}, \bar{R}_{s t . j}$ and $\bar{T}_{s t . j}$. 
The forces are shown on Figure 4 and the horizontal component of force $\bar{T}_{s t . j}$, referred to in Eq. (22), will be obtained from:

$$
\bar{T}_{s t . j}=\frac{M_{s t . j}}{h} \bar{x}_{s t . j}
$$

with $\bar{x}_{s t . j}$ being derived from Eq. (6) and the reaction moment $M_{s t . j}$ from Eq. (19) in which the centre of rotation of the panel $\left(\bar{C}_{p . j}\right)$ will be replaced with that of the $j$ th stud, and the direction of the stud-to-frame reaction, $\bar{F}$, will be in accordance with Eq. (23), rather than Eq. (16).

\subsection{Rotating header beam}

As already pointed out, the iterative procedure described in section 2.1 is based on the assumption of translational fixity for the stud-to-beam connections. Such a 'fully hinged frame' model can (in principle) only be applied to assess the racking behaviour of timber framed walls in which the axial uplift of the windward stud is negligible. Conversely, for partially anchored framed walls, the mechanism of 'separation' between studs and beams, due to the overturning moment, must be taken into account. Such a separation mechanism can be modelled by using pairs of horizontal and vertical springs at each stud-to-beam connection [15] in which the corresponding load-slip curves describe connection behaviour under horizontal (i.e. shear) and vertical (i.e. axial) forces. Adopting this approach in a rigid body analysis would significantly increase the number of degrees of freedom (DoFs) for the timber frame mechanism, generating three DoFs (two translations and a rotation) for each stud and beam making up the frame. In order to keep the model as simple as possible, an alternative approach is to only add the DoF that is most relevant in the separation mechanism between studs and beams. From observations based on laboratory tests on partially anchored walls [25] it can be deduced that such a DoF corresponds to the vertical uplift of the studs at the bottom rail connections. This leads to the insertion of a further DoF for each stud in the frame, in addition to the horizontal displacement of the header beam (i.e. $\Delta_{h}$ ).

However, by retaining the assumption of rigid behaviour of the frame members, it can be shown that the uplift displacement of all the studs can be expressed in terms of just a single variable, namely: the inclination angle $(\beta)$ of the header beam with respect to the horizontal direction (see Figure 5). Setting the uplift displacement of the $j$ th stud as $s_{\text {st.j. }}^{a x .}$, it can be expressed in terms of $\beta$ as follows:

$$
s_{s t . j}^{a x .}=b \frac{j-1}{n_{s t .}-1} \beta
$$




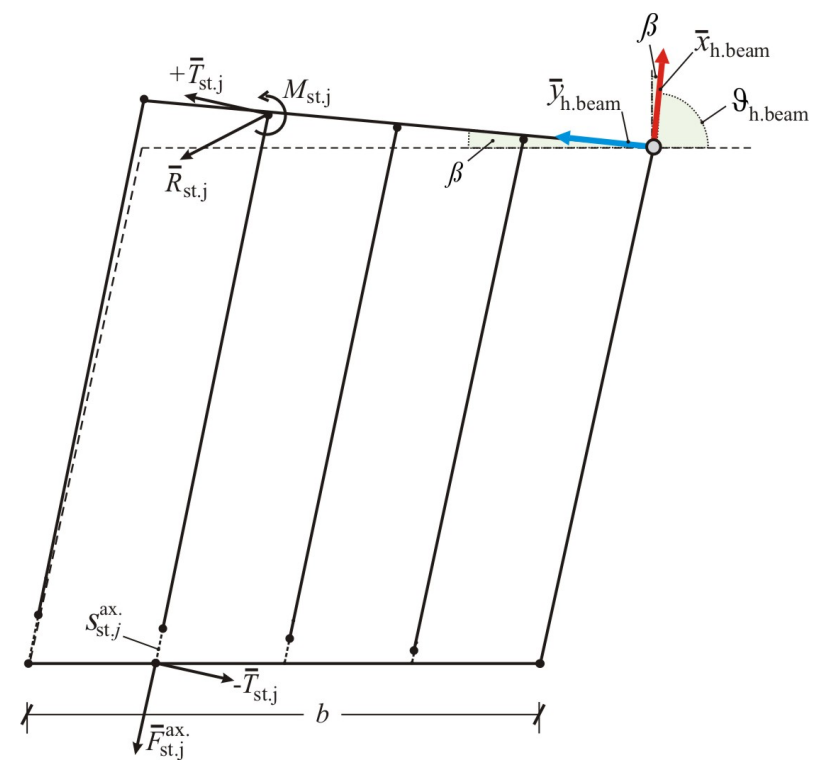

Figure 5: Parametrisation of the timber frame deformed geometry in terms of horizontal and rotational $(\beta)$ displacement of the header beam.

which, rearranged in terms of header beam's orientation angle, $\vartheta_{\text {h.beam }}$, becomes:

$$
s_{\text {st.j. }}^{a x .}=b \frac{j-1}{n_{\text {st. }}-1}\left(\frac{\pi}{2}-\vartheta_{h . b e a m}\right)
$$

Unlike the fully hinged model, where the orientation angle of the header beam was set to a fixed value (see second of Eqs. (7)), in the rotating header beam model, $\vartheta_{\text {h.beam }}$ becomes part of the problem's unknowns. As for the sheathing panel's orientation angles, the value of $\vartheta_{\text {h.beam }}$ must be derived iteratively, and to do so, the resulting out-of-balance moment of the header beam, $M_{h . b e a m}$, must be computed at each time increment as follows:

$$
\begin{aligned}
& M_{\text {h.beam }}=M_{\text {conn. }}+M_{\text {stab. }}+ \\
& +\sum_{j=1}^{n_{s t .}}\left(R_{s t . j, y}+T_{s t . j, y}\right)\left(C_{s t . j, x}-C_{h . b e a m, x}\right)-\left(R_{s t . j, x}+T_{s t . j, x}\right)\left(C_{s t . j, y}-C_{h . b e a m, y}\right)
\end{aligned}
$$

in which:

$$
\bar{R}_{s t . j}=\left[\begin{array}{c}
R_{s t . j, x} \\
R_{s t . j, y}
\end{array}\right] ; \quad \bar{T}_{s t . j}=\left[\begin{array}{c}
T_{s t . j, x} \\
T_{s t . j, y}
\end{array}\right]
$$

have been previously defined in section 2.1.4. $M_{\text {conn }}$. is the out-of-balance moment due to the reactions of the connections between the header beam and sheathing panels (see Eq. (19)), whilst $M_{\text {stab. }}$ is the stabilising moment effect of the applied vertical load, $Q$, 
acting on the header beam, together with the effect of the stud-to-beam connections holding down the studs (see Figure 5):

$$
M_{s t a b .}=Q \frac{b}{2}+\sum_{j=1}^{n_{s t .}} b \frac{j-1}{n_{s t .}-1} F_{s t . j}^{a x}
$$

The tensile reaction force $F_{\text {st.j }}^{a x}$ acting at the bottom of the $j$ th stud, is obtained by inserting the corresponding slip, $s_{\text {st.j }}^{a x .}$ (obtained from Eq. (26)) into the relevant load-slip function $f(s)$. Such a function $f(s)$ is only required for the tensile part of the stud-to-beam load-slip curve. For compression forces, a mono-lateral constrain can be added to the frame system in order to simulate the contact between the studs' bottom ends and the sole plate (bottom beam) using the following conditional statement at the end of each iteration cycle:

$$
\begin{aligned}
& \text { If } \vartheta_{h . b e a m}^{t+\Delta t} \text { [as from Eq. (13)] }>\frac{\pi}{2} \\
& \text { Then: } \vartheta_{\text {h.beam }}^{t+\Delta t}=\frac{\pi}{2}
\end{aligned}
$$

and with this approach, rigid behaviour for the stud-to-beam connections is simulated under compressive forces.

By modelling as described, the behaviour of the timber frame resulting from the 'rotating header beam' model equates to a mechanism having only two DoFs, corresponding to the horizontal and rotational displacements of the header beam $\left(\Delta_{h}\right.$ and $\beta$ respectively).

\section{Calculations}

The numerical method described in the paper has been implemented using Python ${ }^{\text {TM }}$ programming language and the results have been compared with those obtained from laboratory tests on unit wall panels. The results are given in section 3.3.

\subsection{Laboratory test set up}

The unit wall geometry considered for the raking test is shown in Figure 6-a. Material and geometric properties of the unit wall's components and fastening are summarised as follows:

- For the studs and beams:

- Cross-section: $44 \mathrm{~mm} \times 95 \mathrm{~mm}$.

- Strength Class: C16 [27]. 


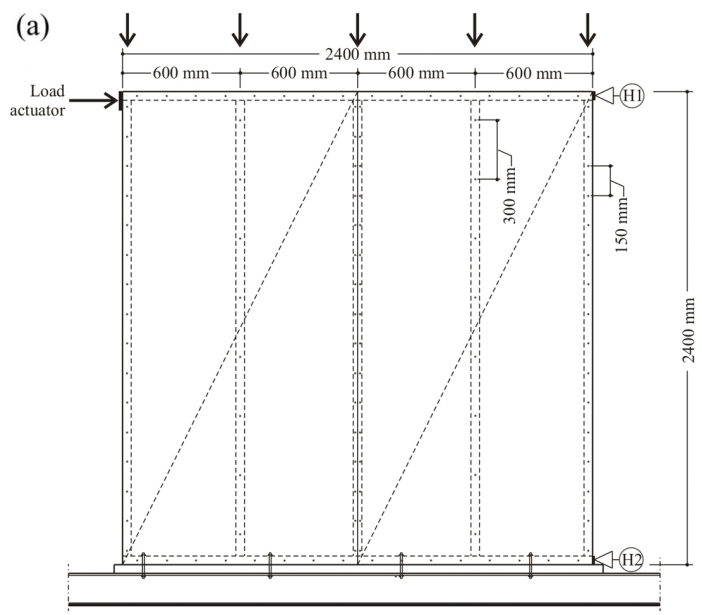

(b)

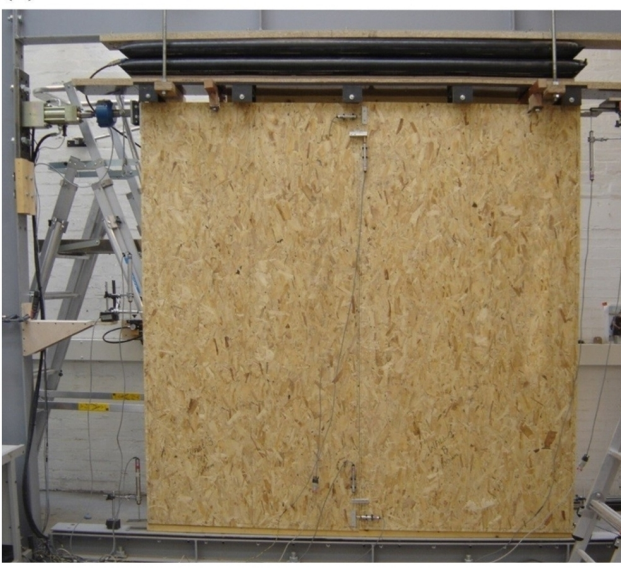

Figure 6: Raking test of timber framed wall carried out in accordance with BS EN 594:2011 [26]: (a) Test set up and wall's dimensions. (b) Execution of the test.

- For the panels:

- Thickness: $9 \mathrm{~mm}$.

- Material: OSB/3 [28].

- Gap between adjacent panels: $3 \mathrm{~mm}$.

- For each panel-to-frame connection:

- 1 bright smooth wire nail: $3.0 \mathrm{~mm}$ diameter $\times 52 \mathrm{~mm}$ long.

- Spacings: $150 \mathrm{~mm}$ (around the panel perimeter); $300 \mathrm{~mm}$ (along intermediate studs).

- For each stud-to-beam connection:

- 2 screws, $3.2 \mathrm{~mm}$ diameter (smooth shank) $\times 75 \mathrm{~mm}$ long.

The types of fastener used for the connections are shown in Figure 7.

Three wall specimens were tested with a vertical load applied on top of the header beam. A pressurised air-bag device, positioned on rollers between the header beam of the wall and the overlying loading rig cross-bar, was constructed for this purpose (see Figure 6-b). The internal air pressure was calibrated to generate a (total) load of 25 $\mathrm{kN}$ acting on the header beam. The racking tests were carried out in accordance with the requirements of BS EN 594:2011 [26]. A sole plate was placed between the bottom rail of the unit wall and the test rig base, onto which the bottom rail was fixed by four bolted connections (see Figure 6). A horizontal load was then applied to the upper-left 
(a)

(b)

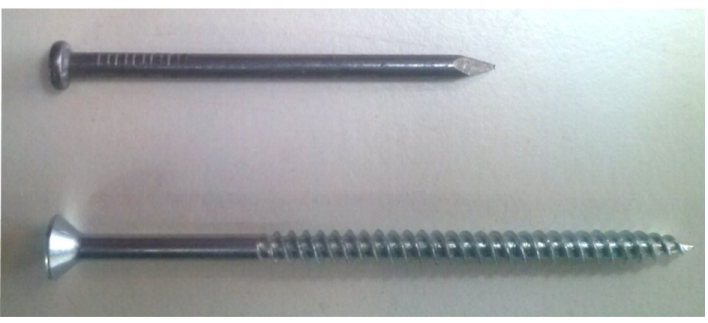

Figure 7: (a) Bright smooth wire nail $3.0 \mathrm{~mm}$ diameter $\times 52 \mathrm{~mm}$ long, for the stud-to-beam connections. (b) Screw for the stud-to-beam connections: $3.2 \mathrm{~mm}$ diameter (smooth shank) $\times 75 \mathrm{~mm}$ long.

corner of the wall whilst two linear transducers ( $\mathrm{H} 1$ and $\mathrm{H} 2)$ were used to take readings of the deformation.

With reference to Figure 6-a, the experimental horizontal displacement $\Delta_{h}$ was derived for each load increment from the difference between the horizontal displacement of the header beam and bottom rail as follows:

$$
\Delta_{h}=\Delta_{\mathrm{H} 1}-\Delta_{\mathrm{H} 2}
$$

\subsection{Input parameters for the numerical model}

The load-slip curves of the panel-to-frame connections, which were required to derive the $f(s)$ function, were obtained from tests on six samples of sheathing-to-timber connections. Each test comprised four $3.0 \mathrm{~mm}$ diameter nails and two different set-up arrangements were used. Three samples were tested with the panel material loaded towards its edge, to cover for possible edge failure of the panel material, and three with the panel material loaded away from its edge. The test set-up used for each test is shown in Figures 8-a and 8-c respectively. The experimental load-slip curves from the two test set-ups have been averaged to obtain two discrete lists of points, and applying the five-parameters approach proposed by Girhammar et al [24], the corresponding continuous function, $f(s)$, has been derived:

$$
f(s)=\left(F_{0}+K_{1} s\right)\left[1-e^{\left(-\frac{K_{0} s}{F_{0}}\right)}\right] e^{\left(-\frac{s^{\alpha}}{\beta}\right)}
$$

The values of the five parameters $\left(F_{0}, K_{0}, K_{1}, \alpha\right.$ and $\left.\beta^{2}\right)$ to insert into Eq. (32) were computed with the Microsoft Excel ${ }^{\circledR}$ add-in solver for non-linear regression analysis [29].

\footnotetext{
${ }^{2}$ Not to be confused with the rotational displacement of the header beam, as from Eq. (25).
} 
(a)

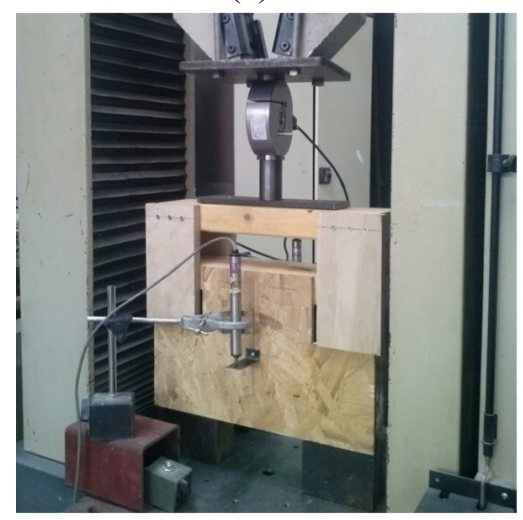

(c)

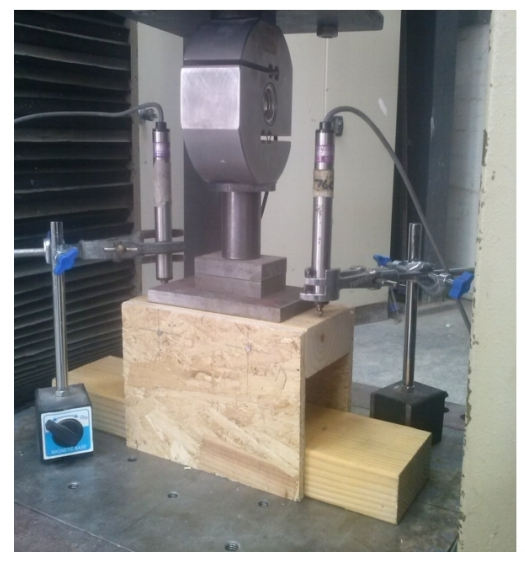

(b)

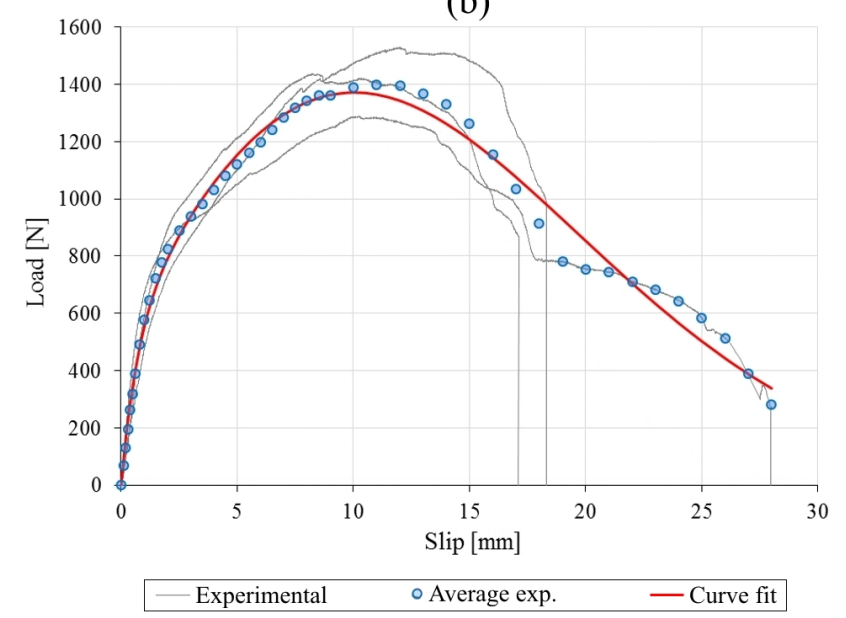

(d)

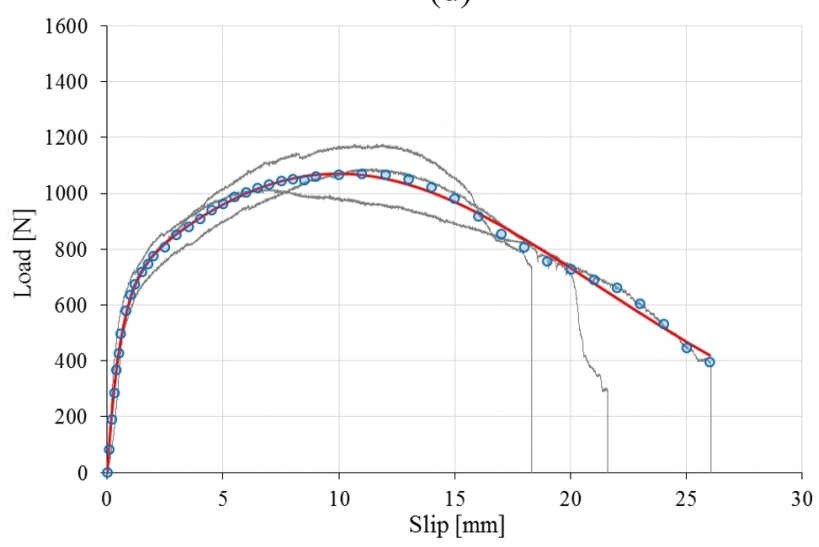

Figure 8: Load-slip relationship for the panel-to-frame connections with $3.0 \mathrm{~mm}$ diameter $\times 52 \mathrm{~mm}$ long nails. (a) Set-up with the panel loaded towards its edge and (b): the corresponding best curve fitting. (c) Set-up with the panel loaded away from its edge and (d): the corresponding best curve fitting. The average experimental values (round markers) have been fitted (bolt line) with the function given in Eq. (32)).

The load-slip curves obtained from tests with the panels loaded away from their edge (Figure 8 -d) show a lower ultimate load $(\approx-24 \%$ on average) compared to those obtained by testing the connection with the panels loaded towards their edge (Figure 8-b). This may be due to a reduction of frictional forces, between panel and timber, as a consequence of bending of the panel under the effect of compressive actions exercised by the nails. As the panel-to-frame connections will be loaded in different configurations, an average curve, $f(s)$, has been derived from both test series, as shown in Figure 9. The corresponding values of the five parameters $F_{0}, K_{0}, K_{1}, \alpha$ and $\beta$ are summarised 


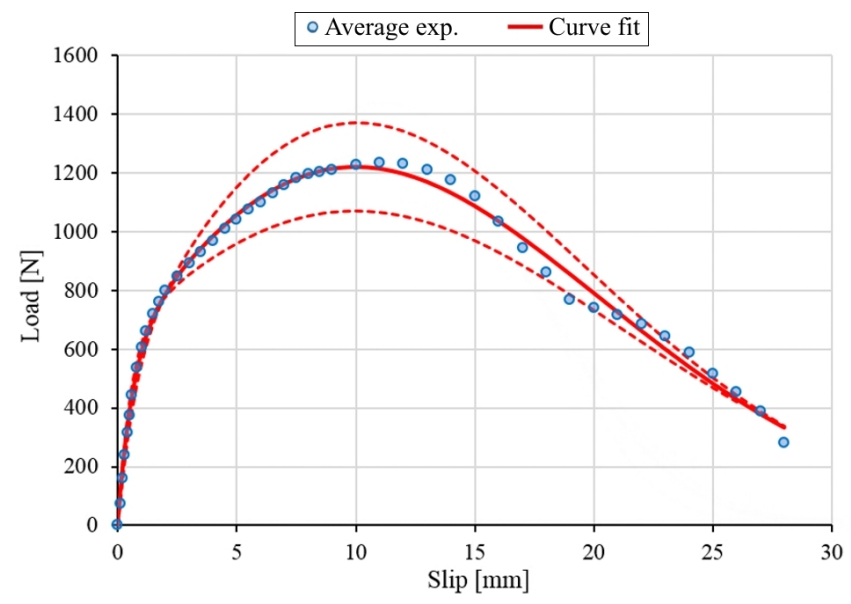

Figure 9: Load-slip relationship for the panel-to-frame connections with $3.0 \mathrm{~mm}$ diameter $\times 52 \mathrm{~mm}$ long nails, obtained as the best fit (bolt line) from average test values (round markers) of six test samples.

(a)

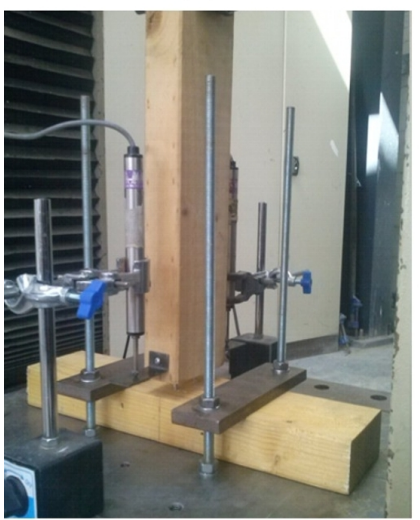

(b)

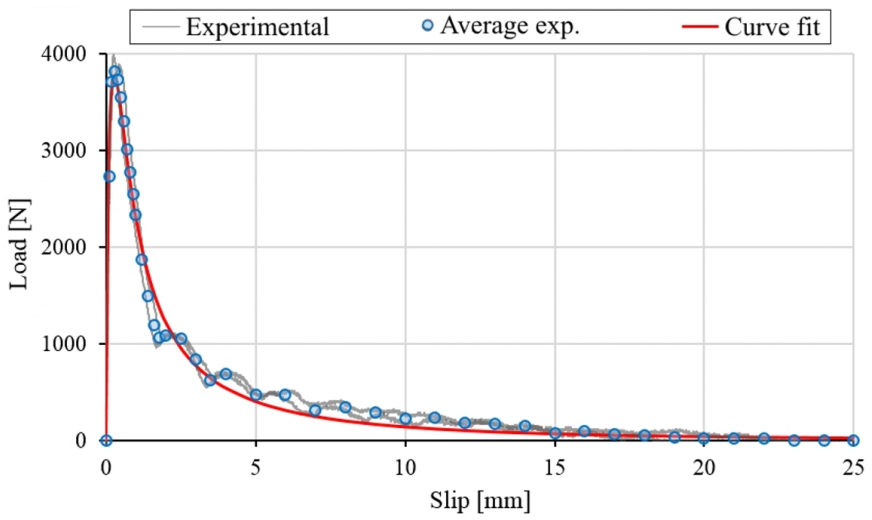

Figure 10: Load-slip relationship for the stud-to-beam connections: (a) test set up. (b) best curve fitting.

in Table 1, together with those computed for the best fit of the stud-to-beam loadslip curves. With regard to the load-slip behaviour of the stud-to-beam connections, two specimens were tested. The set-up for the pulling-out test and resulting curves are shown in Figure 10. The failure mode for this connection occurred by point-side withdrawal of the screws.

Additional input parameters required to run the analysis were set as follows:

- Fictitious mass, $m=9950 \cdot 10^{3}[\mathrm{~kg}]$

- Fictitious moment of inertia $=6965 \cdot 10^{6}\left[\mathrm{~kg} \mathrm{~mm}{ }^{2}\right]$ 
Table 1: Values of the five parameters for best curve fitting of the experimental load-slip curves shown in Figures 9 and 10.

\begin{tabular}{lccccc}
\hline Connection type & $F_{0}$ & $K_{0}$ & $K_{1}$ & $\alpha$ & $\beta$ \\
\hline Panel-to-frame & 595.9712 & 1067.047 & 112.8405 & 1.894718 & 227.5088 \\
Stud-to-beam & 25194.99 & 99743.39 & 2183.394 & 0.376902 & 0.407096 \\
\hline
\end{tabular}

- (Pseudo) time increment, $\Delta t=0.01[\mathrm{~s}]$

- Damping factor for (both) translational and rotational velocities, $\xi=0.995$

- Incremental imposed horizontal displacement, $\Delta_{h}=2 \mathrm{~mm}$

As already mentioned in section 2.1.2: mass, moment of inertia and viscous damping do not have any physical meaning and their values are calibrated to assure numerical stability and fast convergence. The values reported above were set by trial-and-error. For each increment of imposed horizontal displacement, the system was assumed to have reached static equilibrium at fulfilment of the following inequality: $\max \left\{\left\|\bar{R}_{j}\right\|\right\} \leq$ $0.001 \mathrm{kN}$.

\subsection{Comparison of results}

The numerical and experimental load-displacement curves $P_{h}\left(\Delta_{h}\right)$ that have been considered are shown in Figure 11. The numerical curves were derived by using the 'rotating header beam model' with the stabilising moment, $M_{\text {stab. }}$, calculated as from Eq. (29) in which the tensile reaction forces $F_{\text {st.j }}^{a x}$, due to the stud-to-beam connections, was computed according to the load-slip curve shown in Figure 10, whilst the vertical load $Q$ was set equal to $25 \mathrm{kN}$ (as for the tested walls) and $20 \mathrm{kN}$. The experimental curve is the average of three load tests undertaken and each test curve is also shown. All of the walls tested failed by strength with displacements less than the $100 \mathrm{~mm}$ maximum value referred to in BS EN 594:2011. In Figure 11 is also shown the analytical racking strength value of the walls derived according to the PD 6693-1 procedure [12]. The panel-to-frame fastener strength per unit length, required in the PD 6693-1 method, was derived from the average of the fastener strength values obtained from tests (see section 3.2).

\subsubsection{Discussion}

From Figure 11 it can be seen from the tests on the wall panels that they all behave in a relatively ductile manner up to failure. The test result for the strongest wall panel 


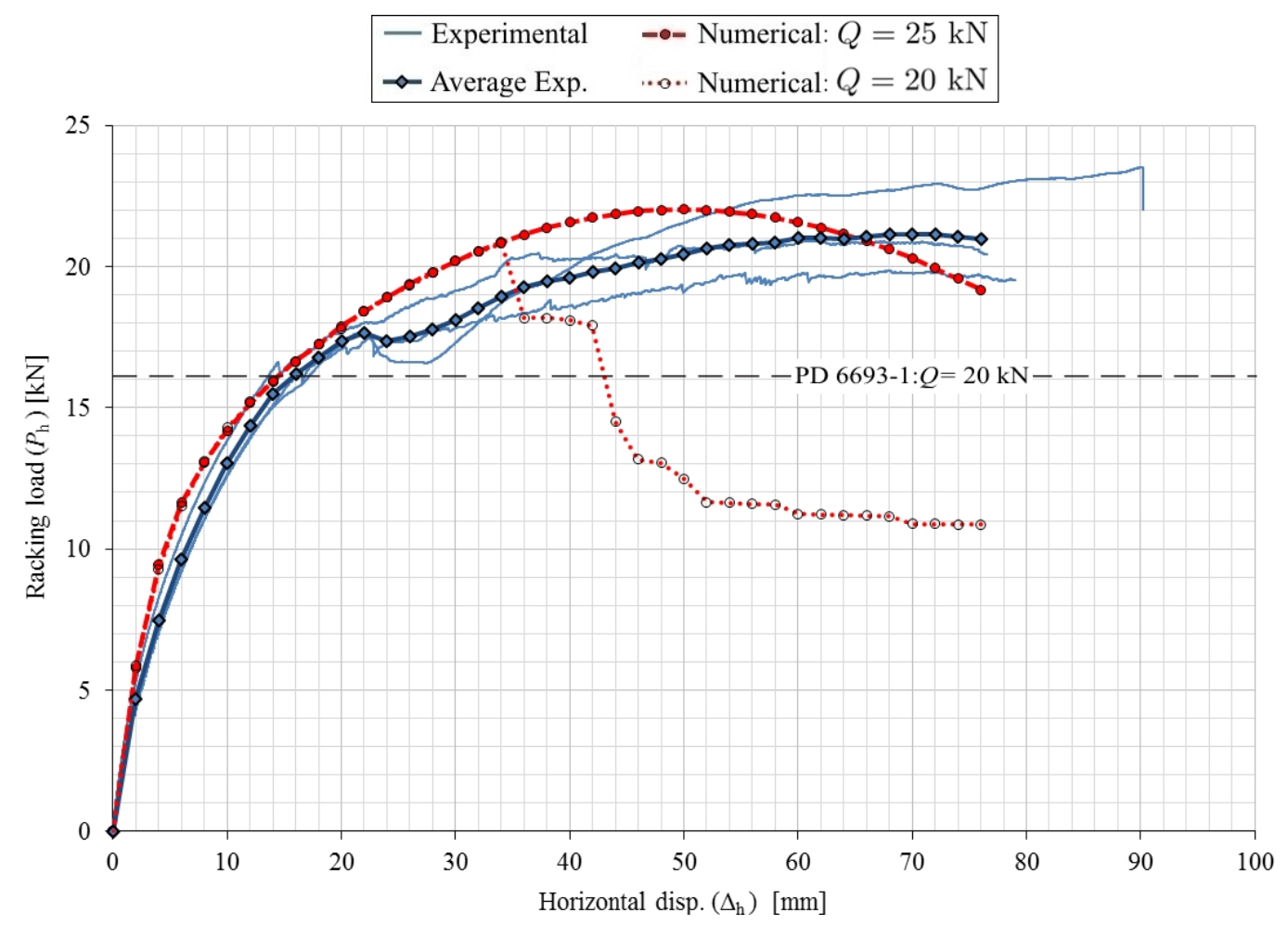

Figure 11: Numerical and experimental load-displacement curves for the unit racking wall. The dashed horizontal line indicates the wall racking strength derived according to PD 6693-1 procedure.

shows a sudden loss of strength at a lateral displacement of $22 \mathrm{~mm}$ but recovered with increasing stiffness to fail at a displacement of $90.3 \mathrm{~mm}$ and the distorted profile of the average curve in the $20 \mathrm{~mm}$ to $30 \mathrm{~mm}$ range is primarily a consequence of the behaviour of that test.

The equivalent numerical model (i.e. with $Q=25 \mathrm{kN}$ ) exhibits similar behaviour to the average test curve up to a displacement of $22 \mathrm{~mm}$ and beyond that value there is a divergence due to the distorted profile of the test curve referred to above.

The average failure load of the tested walls occurred at $21.15 \mathrm{kN}$, with a displacement of $72 \mathrm{~mm}$, while the model predicted a failure load of $22.02 \mathrm{kN}$ at a displacement of 50 $\mathrm{mm}$, i.e. $4.1 \%$ higher than the average test result. Adopting the PD 6693-1 approach, the theory predicts a racking strength value at failure of $16.1 \mathrm{kN}$, which is approximately $24 \%$ less than the average value referred to above.

From the numerical analyses, it has been possible to check the gap reduction between adjacent sheathing panels under extreme movement to confirm that no interaction forces between panels has occurred and it has been found that, for both analyses, the largest 

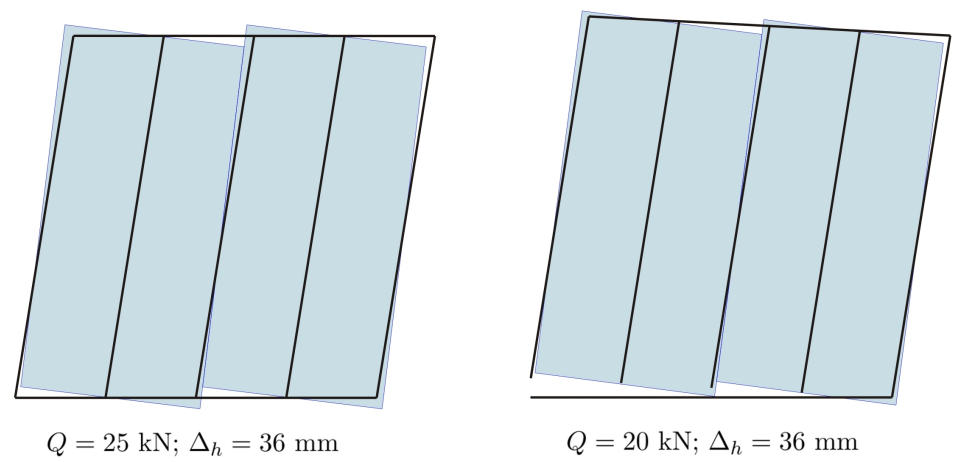

Figure 12: Deformed wall geometries (magnified by a factor of 10) for a value of imposed horizontal displacement $\Delta_{h}=36 \mathrm{~mm}$ : the wall model with $Q=25 \mathrm{kN}$ experiences a pull-out slip of $0.11 \mathrm{~mm}$, at the the bottom end of the windward stud, whilst a pull-out slip value of $1.24 \mathrm{~mm}$ is found for the wall model with $20 \mathrm{kN}$ of imposed vertical load.

gap reduction between adjacent panels was less than $0.2 \mathrm{~mm}$ at their corresponding maximum racking load $\left(P_{h}\right)$.

At loads comparable with the serviceability condition the model overestimates the stiffness behaviour by approximately $18 \%$. A major contribute to this difference is the fact that the model assumes rigid behaviour of the various elements making up the wall panel. Another reason is that the stud-to-beam connections have been modelled as infinitely stiff against lateral forces (i.e. $\bar{T}_{s t . j}$ in Eq. (24)).

From Figure 11, it can also be seen that the raking-displacement curves of the two numerical models (with $Q=20 \mathrm{kN}$ and $Q=25 \mathrm{kN}$ ) follow the same path up to a displacement value of $34 \mathrm{~mm}$, above which, a sudden drop in the raking strength $(-2.96$ $\mathrm{kN}$ ) occurs for the model with $Q=20 \mathrm{kN}$. This is indeed the result of a sudden reduction in tensile strength of the stud-to-beam connection at the bottom end of the windward stud. With reference to Figure 12: for $\Delta_{h}=36 \mathrm{~mm}$ and $Q=25 \mathrm{kN}$, the pull-out slip at the the bottom end of the windward stud is equal to $0.11 \mathrm{~mm}$ (corresponding to a hold down force $F_{s t}^{a x}$. $=3.1 \mathrm{kN}$ ), whilst for the model with $Q=20 \mathrm{kN}$, a pull-out slip of $1.24 \mathrm{~mm}$ is recorded, and for such a value, the corresponding hold down force reduces to $1.9 \mathrm{kN}$ (see Figure 10-b).

\section{Conclusions}

The racking mechanics of timber framed walls is complex, involving several material and geometrical non-linearities, especially with regard to connection behaviour. Because 
of this complexity, it is often felt that the use of $\mathrm{FE}$ analysis software is required in order to cover the number of variables in the analysis. However, designers usually base their wall designs approach on closed-form solutions, and these are invariably based on simplified assumptions for the wall behaviour.

In this paper, the theoretical basis, numerical development and testing of an iterative procedure that models the racking behaviour of Platform timber framed walls, is presented. It involves the application of a rigid body relaxation method based on the Dynamic Relaxation technique. The approach uses simplified kinematics for the timber frame behaviour, similar to that used in most analytical models, but at the same time, takes full account of the non-linearities of connections. With this method, two models have been developed, namely:

- Fully hinged frame

- Rotating header beam

In the 'fully hinged frame' model, the timber frame is assumed to behave as a rigid body mechanism with only one DoF, corresponding to the horizontal displacement of the header beam $\left(\Delta_{h}\right)$ as shown in Figure 2-b. The connections between studs and beams have been modelled as perfect hinges. Furthermore, by assuming the wall panels to be rigid, the remaining unknowns required to fully describe the deformed geometry of the wall are the position and orientation angle of the rigid body panels, and these have been derived using a numerical relaxation technique. From the results, the racking load and stiffness behaviour of the wall can be derived. In the 'rotating header beam' model a further DoF, corresponding to the rigid body rotation of the header beam, is added to the kinematics of the timber frame. As shown in Figure 5, the introduction of such a rotational DoF enables to take into account the effects of separation at the connections between bottom ends of the studs and bottom rail, allowing partially anchored walls to be modelled.

The 'rotating header beam' model has been compiled using Python ${ }^{\mathrm{TM}}$ and its output compared with that obtained from laboratory tests on three full scale timber framed walls, as well as with the racking strength value derived by using the PD 6693-1 method. The maximum racking load predicted numerically is slightly higher than that obtained from the average of tests results, whereas the PD6693-1 method gives a failure value which is only about $76 \%$ of that value.

The numerical model overestimated the racking stiffness at loading comparable with the wall serviceability condition. Because of the assumption of rigid behaviour of all 
of the wall members, and the reduced number of DoFs that have been used to model the kinematics of the timber frame, it is to be expected there will be some difference between the model and test behaviour.

\section{Acknowledgements}

The Centre for Timber Engineering and The School of Engineering and the Built Environment, Edinburgh Napier University are gratefully acknowledged for supporting the described work.

\section{References}

[1] R. Hairstans, Optimisation of timber platform frame construction, Ph.D. thesis, Edinburgh Napier University (2007).

[2] A. Gibb, F. Isack, Re-engineering through pre-assembly: client expectations and drivers, Building Research \& Information 31 (2) (2003) 146-160. doi:10.1080/ 09613210302000.

[3] K. J. Leitch, The development of a hybrid racking panel, Ph.D. thesis, Edinburgh Napier University (2012).

[4] B. Källsner, U. A. Girhammar, Analysis of fully anchored light-frame timber shear walls - elastic model, Materials and Structures 42 (3) (2009) 301-320. doi:10. $1617 / \mathrm{s} 11527-008-9463-\mathrm{x}$.

[5] B. Källsner, U. A. Girhammar, Plastic models for analysis of fully anchored lightframe timber shear walls, Engineering Structures 31 (9) (2009) 2171-2181. doi: $10.1016 / j$.engstruct.2009.03.023.

[6] D. Casagrande, S. Rossi, T. Sartori, R. Tomasi, Proposal of an analytical procedure and a simplified numerical model for elastic response of single-storey timber shearwalls, Construction and Building Materials 102 (2016) 1101-1112. doi:10.1016/ j. conbuildmat.2014.12.114.

[7] D. Casagrande, S. Rossi, R. Tomasi, G. Mischi, A predictive analytical model for the elasto-plastic behaviour of a light timber-frame shear-wall, Construction and Building Materials 102 (2016) 1113-1126. doi:10.1016/j.conbuildmat.2015. 06.025. 

framed shear walls, in: 8th World Conference on Timber Engineering, 2004, pp. 129-134.

[9] B. Källsner, U. Girhammar, Plastic design of partially anchored wood-framed wall diaphragms with and without openings, in: Proceedings CIB/W18 Meeting, 2005, pp. 29-31.

[10] B. G. Neal, The plastic methods of structural analysis, Chapman and Hall London, 1977.

[11] UK National Annex to BS EN 1995-1-1:2004+A1:2008. Eurocode 5: Design of timber structures - Part 1-1: General - Common rules and rules for buildings, British Standards Institution.

[12] PD 6693-1:2012. Recommendations for the design of timber structures to Eurocode 5: Design of timber structures — Part 1-1: General — Common rules and rules for buildings, British Standards Institution.

[13] J. Porteous, A. Kermani, Structural timber design to Eurocode 5, John Wiley \& Sons, 2013.

[14] W. Pang, M. H. Shirazi, Next generation numerical model for non-linear in-plane analysis of wood-frame shear walls, in: 11th World Conference on Timber Engineering 2010, WCTE 2010, 2010.

[15] J. Vessby, B. Källsner, A. Olsson, U. A. Girhammar, Evaluation of softening behaviour of timber light-frame walls subjected to in-plane forces using simple FE models, Engineering Structures 81 (2014) 464-479. doi:10.1016/j.engstruct. 2014.09 .032$.

[16] M. Criesfield, Non linear finite element analysis of solids and structures, vol. 1 (1991).

[17] A. S. Day, An introduction to dynamic relaxation, The Engineer 29 (1965) 218-221.

[18] M. R. Barnes, Form finding and analysis of tension structures by dynamic relaxation, International journal of space structures 14 (2) (1999) 89-104. doi: $10.1260 / 0266351991494722$. 
[19] S. Adriaenssens, M. Barnes, Tensegrity spline beam and grid shell structures, Engineering structures 23 (1) (2001) 29-36. doi:10.1016/S0141-0296(00)00019-5.

[20] B. D'Amico, A. Kermani, H. Zhang, Form finding and structural analysis of actively bent timber grid shells, Engineering Structures. 81 (2014) 195-207. doi:10.1016/ j.engstruct.2014.09.043.

[21] A. Liew, T. VanMele, P. Block, Vectorised graphics processing unit accelerated dynamic relaxation for bar and beam elements, in: Structures, Vol. 8, 2016, pp. 111-120. doi:10.1016/j.istruc.2016.09.002.

[22] P. J. Davis, P. Rabinowitz, Methods of numerical integration, Courier Corporation, 2007.

[23] B. DAmico, A. Kermani, H. Zhang, P. Shepherd, C. J. K. Williams, Optimization of cross-section of actively bent grid shells with strength and geometric compatibility constraints, Computers \& Structures 154 (2015) 163-176. doi: $10.1016 / j$. compstruc. 2015.04 .006 .

[24] U. A. Girhammar, N. I. Bovim, B. Källsner, Characteristics of sheathing-to-timber joints in wood shear walls, in: 8th world conference on timber engineering, 2004, pp. $165-170$.

[25] U. A. Girhammar, B. Källsner, Tests on partially anchored wood-framed shear walls, in: 8th world conference on timber engineering, 2004.

[26] BS EN 594:2011 Timber structures - Test methods - Racking strength and stiffness of timber frame wall panels, British Standards Institution.

[27] BS EN 338:2009 Structural timber - Strength classes, British Standards Institution.

[28] EN 300:2006 Oriented Strand Board (OSB) - Definitions, classification and specifications, European Standards.

[29] A. M. Brown, A step-by-step guide to non-linear regression analysis of experimental data using a microsoft excel spreadsheet, Computer methods and programs in biomedicine 65 (3) (2001) 191-200. doi:10.1016/S0169-2607(00)00124-3. 